\title{
Nitrogen and Boron Doped Diamond Like Carbon Thin Films Synthesis by Electrodeposition from Organic Liquids and Their Characterization
}

\author{
Sunita Kundoo ${ }^{1 *}$, Satyajit Kar ${ }^{2}$ \\ ${ }^{1}$ Department of Physics, Government College of Engineering and Leather Technology, Kolkata, India \\ ${ }^{2}$ Department of Physics, Ramakrishna Mission Sikshanamandira, Belur Math, Howrah, India \\ Email: *skundoo@yahoo.com
}

Received January 6, 2013; revised February 7, 2013; accepted February 28, 2013

\begin{abstract}
Thin films of amorphous diamond like carbon (a:DLC) were deposited by using a novel technique. By electrodeposition from methanol-camphor solution thin a:DLC films were deposited on non-conductive glass substrates and also on high resistive Si substrates, by using a fine wire mesh electrode, at atmospheric pressure and temperature below $350 \mathrm{~K}$. Thin films of a:DLC were doped by incorporation of nitrogen (a:N-DLC) and boron (a:B-DLC) using urea and boric acid with methanol-camphor solution respectively during the electrodeposition process. From transmittance measurements in the UV-VIS-NIR region, the optical energy band gap of about $1.0 \mathrm{eV}$ for undoped a:DLC film, $2.12 \mathrm{eV}$ for a:N-DLC and $2.0 \mathrm{eV}$ for a:B-DLC films were determined. The spectra showed high transparency in the visible and NIR region. Fourier transform infrared spectroscopy (FTIR) measurements showed the appearance of various C-H and C-C bonding in the spectrum of undoped amorphous DLC film and confirmed $\mathrm{C}-\mathrm{N}$ and $\mathrm{C}=\mathrm{N}$ bond formation in a:N-DLC film. From the temperature variation of d.c. conductivity studies, the activation energies were determined and found to be $0.75 \mathrm{eV}$, $0.32 \mathrm{eV}$ and $0.58 \mathrm{eV}$ for undoped a:DLC films, a:N-DLC and a:B-DLC films respectively. Electrical resistivity at room temperature was reduced by the doping effect, from $10^{9} \Omega$-cm for undoped films to $10^{7} \Omega$-cm for nitrogen doped films and $10^{8} \Omega$-cm for boron doped films.
\end{abstract}

Keywords: Non-Crystalline Materials; Thin Films; Infrared Spectroscopy; Electrical Conductivity; Optical Properties

\section{Introduction}

Amorphous diamond like carbon (a:DLC) films have some interesting properties such as high mechanical hardness, dielectric strength, chemical inertness, low wear and friction, optical transparency in the visible and IR range, high resistivity and low band gap. These properties are promising for a wide range of applications such as mechanical, optical, electronic and medical applications. A large number of different techniques have evolved for the deposition of amorphous diamond like carbon films during the last two decades, the majority of the techniques reported so far involved chemical vapor deposition (CVD) [1-4]. Also, various attempts have been made to dope a:DLC films with different elements such as nitrogen [5,6], iodine [7], boron [8], phosphorous [9], fluorine [10] and metal element [11]. They showed that the doping processes significantly affect the electrical, optical and mechanical properties of a:DLC films. But all theses are vacuum deposition processes. The high vacuum required

\footnotetext{
${ }^{*}$ Corresponding author.
}

in the vapor deposition technique makes the equipment rather complicated and the control of the experiment difficult. Also high substrate temperature limits the application of these materials. Compared to the vapor deposition techniques, the electrodeposition from liquid phase has a number of advantages such as, the simplicity of the apparatus and this process can be performed at atmospheric pressure and at nearly room temperature. This process is also attractive because of its low production cost and easy scalability.

Only in recent years several attempts have been made to synthesize diamond like carbon films by electrodeposition from various organic liquids under high voltages $[12,13]$. Very recently, we have demonstrated the synthesis of crystalline carbon nitride by the method of electrodeposition [14]. But, for all these processes conducting indium tin oxide (ITO) coated glass or semiconducting $\mathrm{Si}$ were used as substrates. The obvious reason for choosing these substrates is, here the substrate itself acts as cathode electrode which must be conducting. But the deposition of a:DLC films directly on transparent non- 
conductive substrates like glass, silica etc. is always more attractive because of its number of useful applications in optics. In our knowledge there is no published report on the deposition of a:DLC films on nonconductive substrates by the method of electrodeposition. We have demonstrated a new method to deposit amorphous diamond like carbon films on glass substrates by using a fine wire mesh electrode placed very near to it and by electrolysis of methanol-camphor solution. Also, in this paper we have reported the doping effect of nitrogen and boron on a:DLC films. The doping has been achieved by electrolysis of methanol-camphor-urea and methanolcamphor-boric acid solution for nitrogen and boron respectively. By optimizing the distance of separation between the wire mesh and substrate and also between substrate and the anode (graphite), it is possible to deposit a uniform film. In optical devices a:DLC films can be used as hard transparent coatings. During a:DLC film deposition on conducting ITO coated glass, the substrate becomes insulating after first layer of film deposition, thereby causing difficulty in depositing films with a thickness suitable for any device fabrication. So, our method of depositing a:DLC films on insulating glass substrates by the electrolysis of organic solution has a major scientific and technological significance.

\section{Experimental}

The apparatus used in our experiment was a simple electrolytic cell system. The schematic diagram is shown in Figure 1. A fine wire mesh made of Mo was used as the negative electrode. Glass substrate was placed in touch with the wire mesh or at a distance of up to $1 \mathrm{~mm}$ with a suitable spacer.
For FTIR measurement, Si (400) substrate having sheet resistance of several $\mathrm{M} \Omega \mathrm{s}$ was taken, which was cleaned ultrasonically but no etching was performed to remove surface oxide layer. The counter electrode was a graphite plate. The substrate size was $3.5 \times 2.5 \mathrm{~cm}^{2}$. The thickness of the wire mesh was $0.2 \mathrm{~mm}$, and the area of each small square was $1.5 \times 1.5 \mathrm{~mm}^{2}$. The distance between the electrodes was approximately $7 \mathrm{~mm}$. Before deposition the glass substrates were cleaned with mild soap solution, then with distilled water and also by ultrasonic cleaner in acetone and finally degreased in methanol vapor. A d.c. power supply which can be varied from 0 to $3 \mathrm{KV}$ was used to apply high voltages to the cathode. During the deposition processes, voltages were kept constant, but current densities varied.

To deposit amorphous DLC film, methanol-camphor solution was used as the electrolyte. In our experiment camphor was used with the methanol to get more methyl groups in the solution which is favourable for deposition of a:DLC by electrolysis. We observed the synthesis of nano-diamond films produced from chemical vapor deposition of camphor [15]. In camphor $\left(\mathrm{C}_{10} \mathrm{H}_{16} \mathrm{O}\right)$ there are three carbon atoms attached to three methyl groups while the remaining seven carbon atoms are associated with a ring structure (Figure 2).

It is believed that the methyl radical plays a key role in depositing diamond and DLC films, hence it is expected that organic compounds such as camphor which generate larger number of methyl groups may act as better precursor. The solution was prepared by mixing $5.0 \mathrm{gm}$. of camphor $(>99.5 \%)$ per 1 liter of analytically pure methanol (99.9\%). As the dielectric constant $(\varepsilon)$ of methanol is higher (32.70) [16] and the growth rate of deposited

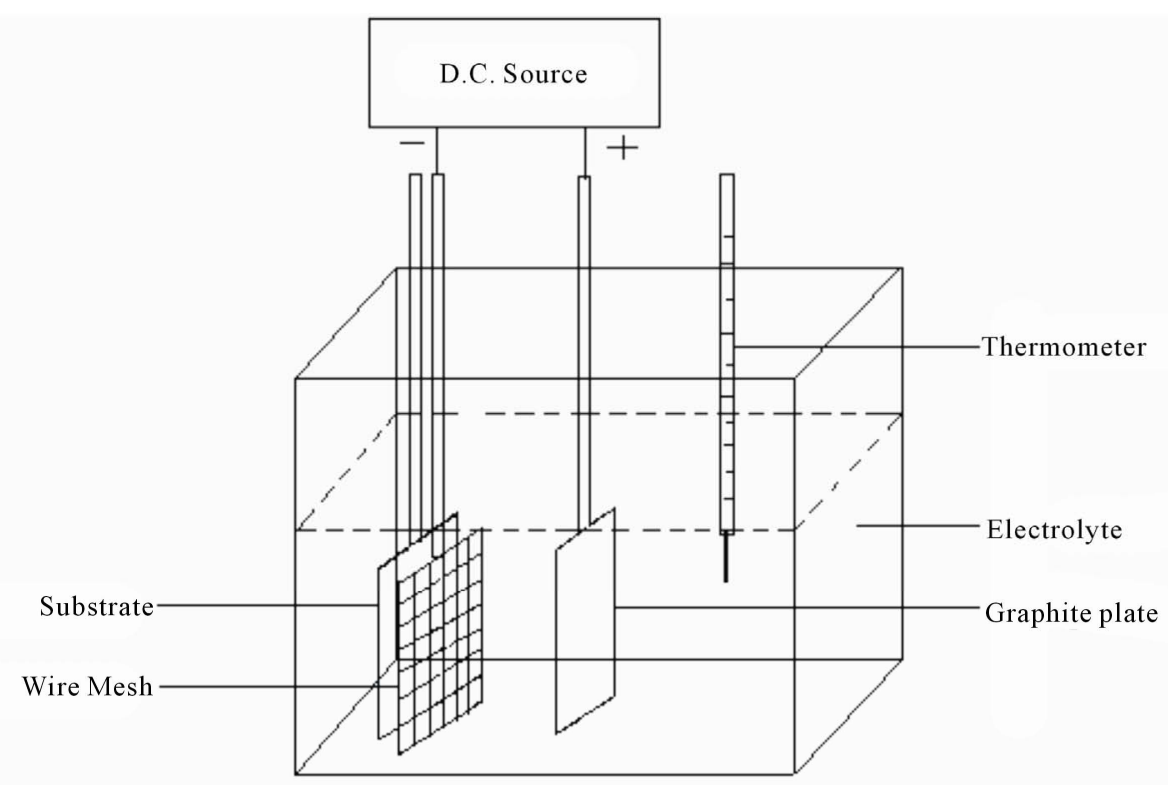

Figure 1. Schematic diagram of the apparatus used for electrodeposition of DLC films. 


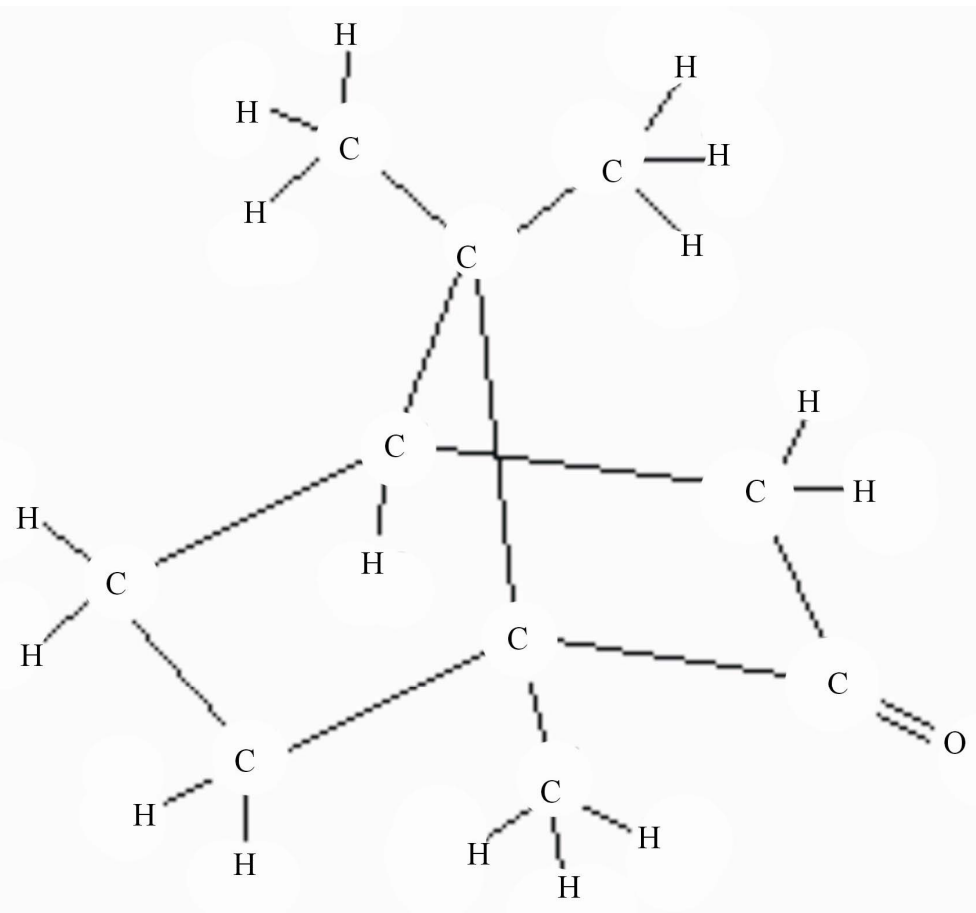

Figure 2. Structure of camphor.

films increased with the increase of $\varepsilon$ values, so methanol was used as the source solution instead of using any other solution containing ethyl groups.

For nitrogen doping in a:DLC films, methanolcamphor-urea solution was used for the electrodeposition process $5.0 \mathrm{gm}$ camphor and $0.5 \mathrm{gm}$ of urea $\left(\mathrm{CO}\left(\mathrm{NH}_{2}\right)_{2}\right)$ $(99.5 \%)$ were mixed per 1 liter of methanol. For boron doping methanol-camphor-boric acid solution was used as the electrolyte. The solution was prepared by mixing $5.0 \mathrm{gm}$ of camphor and $0.075 \mathrm{gm}$ of boric acid $\left(\mathrm{H}_{3} \mathrm{BO}_{3}\right)$ (99.5\%) per 1 liter of methanol.

A number of experiments were performed varying the distance of separation between the glass plate and the wire mesh. The films deposited with the wire mesh in contact with the substrate showed variable thickness, i.e. larger thickness in areas that are not directly under the wires than the region directly under the wire. But, keeping the wire mesh at a distance of $0.5 \mathrm{~mm}$ from the substrate with some suitable teflon spacer, the deposition of films with uniform thickness has been possible.

In all experiments the electrolysis voltage was kept nearly $1.0 \mathrm{kV}$. During undoped a:DLC deposition the corresponding current was varying from $240 \mathrm{~mA}$ to 180 $\mathrm{mA}$, while for N-DLC and B-DLC corresponding variations were $400 \mathrm{~mA}$ to $200 \mathrm{~mA}$ and $600 \mathrm{~mA}$ to $500 \mathrm{~mA}$ respectively. The temperature of the solution during all the experiments was about $350 \mathrm{~K}$. The deposition time was 40 minutes. The films were characterized by Fourier transform infrared spectroscopy (FTIR), UV-Visible-NIR spectrophotometry, X-ray diffraction (XRD) studies and electrical measurements.

\section{Results and Discussions}

\subsection{Deposition Conditions}

In the deposition process the applied potential was quickly increased to $1.0 \mathrm{kV}$ and held constant. The current density increased linearly with the applied potential. When the deposition started, current density decreased remarkably and then gradually saturated with time. It takes only 10 minutes to decrease the substrate current from $400 \mathrm{~mA}$ to $200 \mathrm{~mA}$. This phenomenon may be ascribed to the increasing resistance of the deposited film on the conducting wire mesh. The deposition mechanism of a:N-DLC and a:B-DLC may be inferred as follows:

Under high voltages, the molecules of $\mathrm{CH}_{3} \mathrm{OH}$ and $\mathrm{CO}\left(\mathrm{NH}_{2}\right)_{2}$ were polarized, two groups became partly discharged and moved in the electric field. The alkyl group $\left(-\mathrm{CH}_{3}\right)$ from methanol and $\left(-\mathrm{NH}_{2}\right)$ radical from urea both with a part of positive charge moved towards the cathode, here the wire mesh electrode. Major percentage of the radicals passed through the small openings of the electrode and deposited on the substrate placed near to it.

In the solution of methanol $\left(\mathrm{CH}_{3} \mathrm{OH}\right)$ and boric acid $\left(\mathrm{H}_{3} \mathrm{BO}_{3}\right)$, they formed a compound, methyl borate $\left(\mathrm{B}\left(\mathrm{OCH}_{3}\right)_{3}\right)$ which dissociated easily in $\mathrm{B}^{3+}$ and $\mathrm{OCH}_{3}^{-}$ ions. The methyl group $\left(-\mathrm{CH}_{3}\right)$ from methanol, which was partly positively charged, and $\mathrm{B}^{3+}$ ion both moved towards cathode and deposited on the substrate placed 
very near to it.

\subsection{Fourier Transform Infrared Spectroscopic Measurements}

Figure 3 shows the FTIR spectra of undoped a:DLC, a:N-DLC films deposited on Si substrates in the same conditions as that of the films deposited on glass substrates.

The spectra were measured in a FTIR spectrometer (Nicolet Magna-750) from 400 to $4000 \mathrm{~cm}^{-1}$ by subtracting the absorption due to the Si substrate. The spectra showed different vibrational modes of various bonding. In the IR spectrum of undoped a:DLC film, the 2958 $\mathrm{cm}^{-1}$ peak is assigned to an asymmetric mode of a saturated $\mathrm{sp}^{3}-\mathrm{CH}_{3}$ group. The band at $2932 \mathrm{~cm}^{-1}$ corresponds to asymmetric $-\mathrm{CH}_{2}$ stretch and the $2850 \mathrm{~cm}^{-1}$ peak is assigned to a symmetric mode of a $\mathrm{sp}^{3}$ bonded $-\mathrm{CH}_{3}$ group. The peaks in the range of $1375-1600 \mathrm{~cm}^{-1}$ are assigned to vibrations due to $\mathrm{sp}^{2}$ carbon bonding. The broad band around $3400 \mathrm{~cm}^{-1}$ can be attributed to $-\mathrm{OH}$ stretching vibrations.

In the IR spectrum of a:N-DLC film, the band at 2923 $\mathrm{cm}^{-1}$ corresponds to the asymmetric $-\mathrm{CH}_{2}$ stretch for a typical hydrocarbon. It can also be observed that there are asymmetric $-\mathrm{CH}_{3}$ stretch mode at $2957 \mathrm{~cm}^{-1}$ and sym- metric stretch mode at $2857 \mathrm{~cm}^{-1}$. All these vibrational frequencies are typical of tetrahedrally bonded carbon ( $\mathrm{sp}^{3}$ bonding) in hydrocarbons. In this spectrum apart from the different $\mathrm{C}-\mathrm{H}$ vibrational bands, few new bands appeared due to nitrogen incorporation. The absorption at $3200-3500 \mathrm{~cm}^{-1}$ suggests the existence of $\mathrm{NH}_{\mathrm{X}}(\mathrm{X}=1,2)$ bonds. The strong absorption at $1400-1700 \mathrm{~cm}^{-1}$ can be attributed to the presence of $\mathrm{C}=\mathrm{N}$ bonds. The absorption bands around $1100-1300 \mathrm{~cm}^{-1}$ can be assigned with C-N stretching vibration. The appearance of these peaks confirms the presence of carbon-nitrogen bond formation in the lattice. Thus nitrogen incorporation in the DLC matrix was confirmed. It was observed from IR spectrum of a:B-DLC film (not shown) that boron was also incorporated in the DLC film.

\subsection{Optical Absorption Studies}

Figure 4 shows the UV-Visible-NIR spectra of undoped a:DLC, a:N-DLC and a:B-DLC films deposited on glass substrates.

The spectra were recorded in a spectrophotometer (Hitachi-U 3410) by subtracting the transmittance of the glass substrate taking as reference. The optical transmission spectra indicated that the films showed high

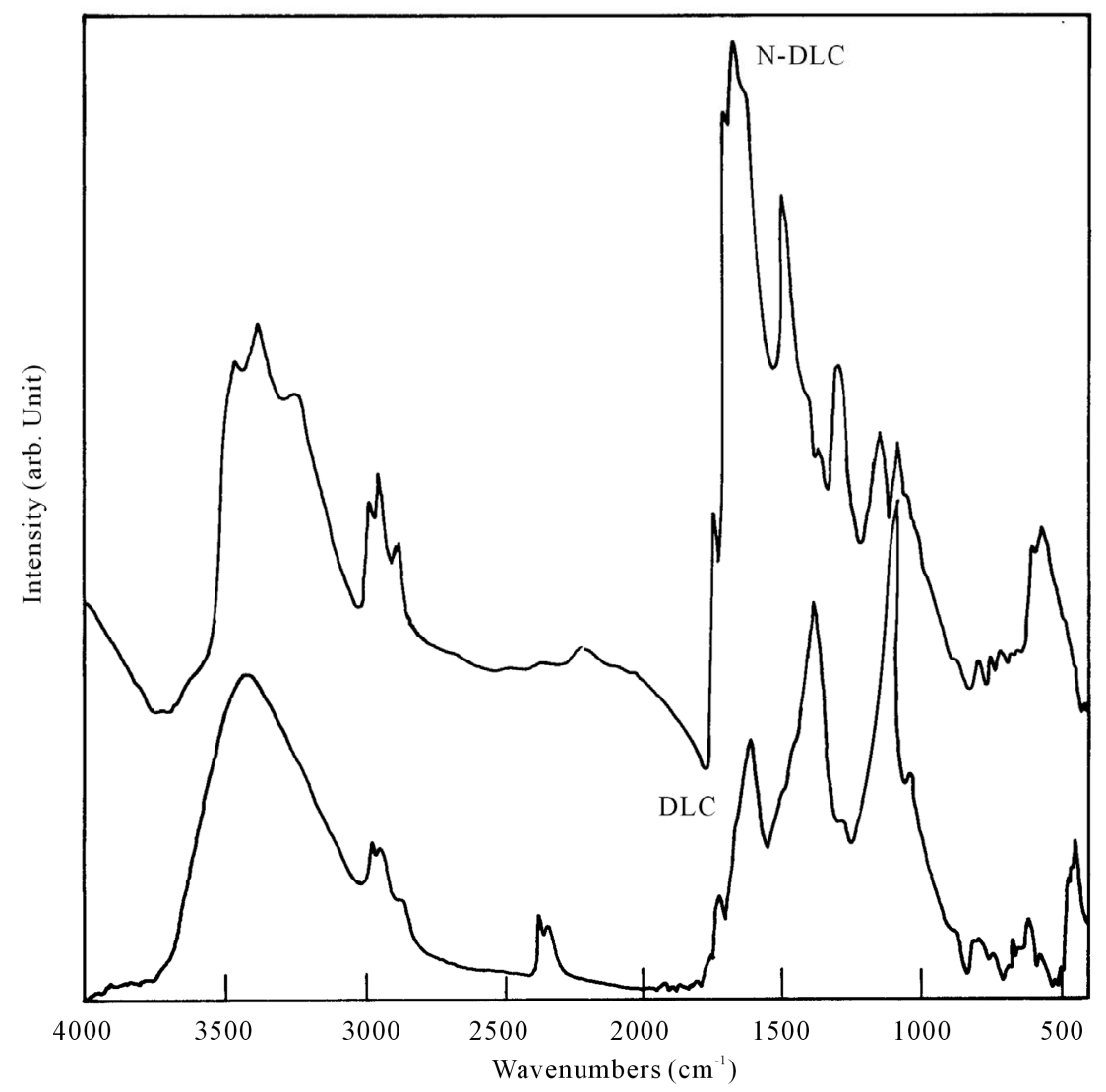

Figure 3. FTIR spectra of undoped a:DLC and a:N-DLC films deposited on Si substrates. 


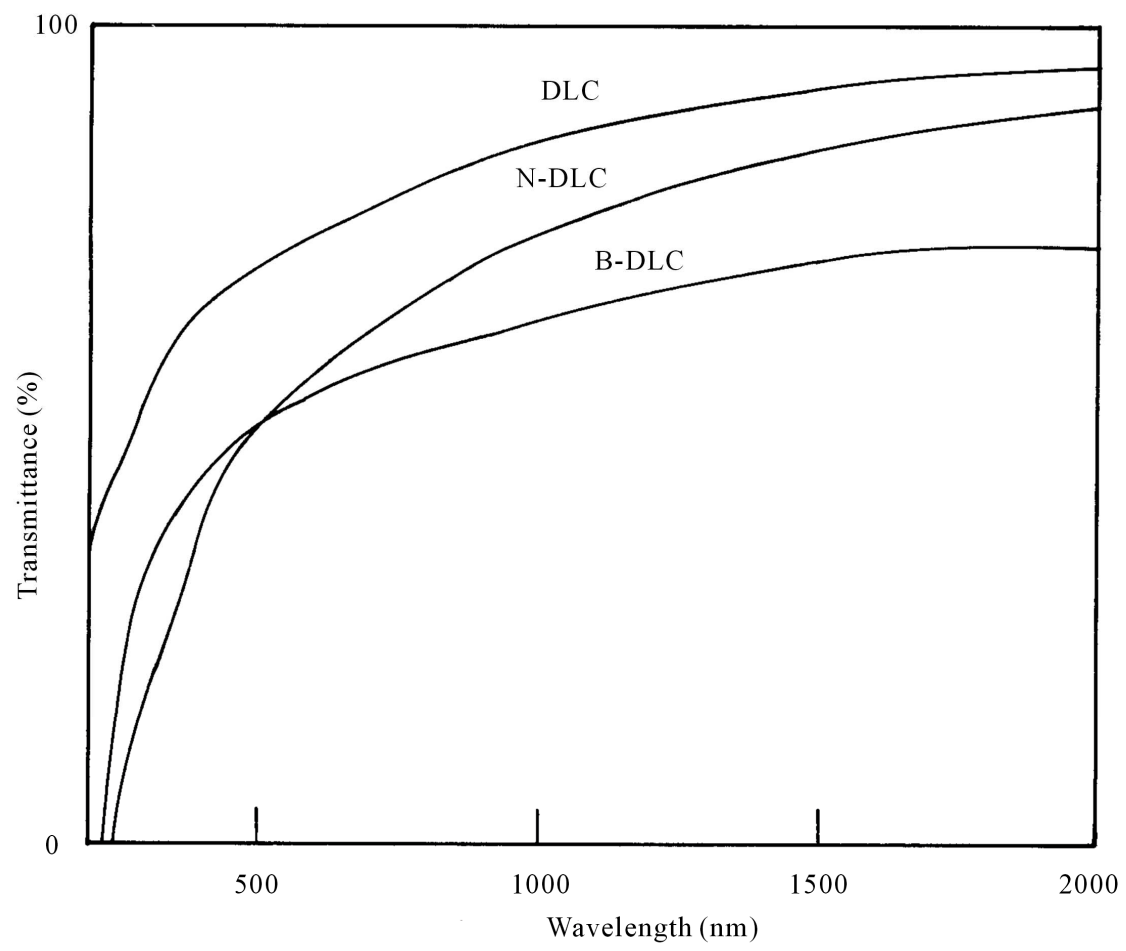

Figure 4. UV-Visible-NIR spectra of undoped a:DLC, a:N-DLC and a:B-DLC films deposited on glass substrates.

transparency in visible and NIR region. The thickness values of the films were determined from SEM crosssectional images to be nearly $1.0 \mu \mathrm{m}$. From transmittance data using Manifacier model [17] absorption co-efficients $(\alpha)$ have been calculated in the region of strong absorption. The fundamental absorption region which corresponds to the electron excitation from valance band to the conduction band, was used to determine the nature and value of the optical band gap.

As the films were amorphous in nature as evident from XRD spectra (not shown here), Tauc relation [18] of absorption co-efficients $(\alpha)$ and the incident photon energy (hv) can be written as:

$$
(\alpha \mathrm{h} v)^{1 / 2}=\mathrm{A}\left(\mathrm{h} v-\mathrm{E}_{\mathrm{g}}\right)
$$

where $\mathrm{A}$ is a constant, $\mathrm{E}_{\mathrm{g}}$ is the band gap of the material. The $(\alpha h v)^{1 / 2}$ vs. hv plots of undoped a:DLC, a:N-DLC and a:B-DLC films are shown in the Figure 5. Extrapolating the linear portion of the graph to the hv axis the indirect band gap values were determined as $1.0 \mathrm{eV}$ for undoped a:DLC, $2.12 \mathrm{eV}$ for a:N-DLC and $2.0 \mathrm{eV}$ for a:B-DLC films. In conclusions, it can be inferred that the nitrogen and boron incorporation increased the optical band gap of a:DLC films. Increase in band gap of a:DLC with nitrogen doping was also found by other workers [7] for their chemical vapor deposited films.

\subsection{Electrical Measurements}

The temperature dependence of d.c. conductivity $(\sigma)$ of undoped and doped amorphous DLC films were measured by standard four probe technique using Kiethley electrometer (Model 6514) in the temperature range of $300-500 \mathrm{~K}$. The experimental $\ln \sigma$ vs. $1 / \mathrm{T}$ plots for a:DLC, a:N-DLC and a:B-DLC films are shown in the Figure 6.

The conductivity in a:DLC films, which increased with increasing temperature at $\mathrm{T}>300 \mathrm{~K}$, suggested a thermally activated conduction mechanism. For extended state conduction the conductivity expression is of the form [19]

$$
\sigma=\sigma_{0} \exp \left(-\mathrm{E}_{\mathrm{a}} / \mathrm{KT}\right)
$$

where, $\mathrm{E}_{\mathrm{a}}$ is the activation energy, $\sigma_{0}$ is a constant.

The values of $\sigma$ were measured and it was found that nitrogen and boron doping caused an increase in the value of room temperature conductivity by two orders of magnitude for nitrogen doped films and one order of magnitude for boron doped films in our described deposition conditions. We have not yet optimized the doping concentration to obtain the lowest possible resistivity. Variation of electrical and optical properties with doping concentration for the electrolysis deposited DLC films will be a topic of future publication. Activation energies were calculated from the slope of $\ln \sigma$ vs. $1 / \mathrm{T}$ plots. Nitrogen doping increased n-type conductivity of a:DLC films, and the nature of n-type conduction was confirmed by hot probe measurement. Due to nitrogen substitution, all the excess electrons condensed into empty gap states 


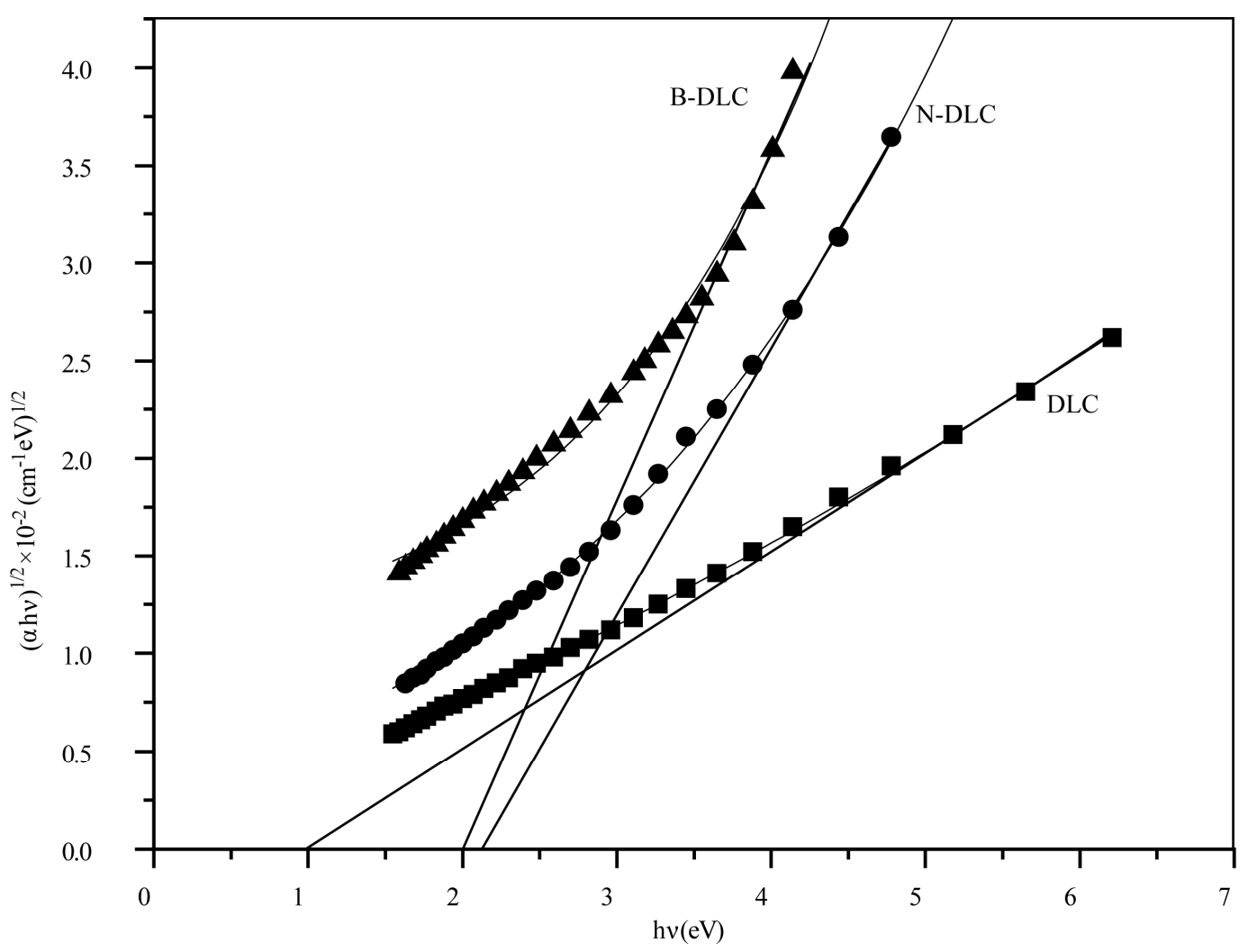

Figure 5. ( $\alpha h v) 1 / 2$ vs. hv plots of undoped a:DLC, a:N-DLC and a:B-DLC films.

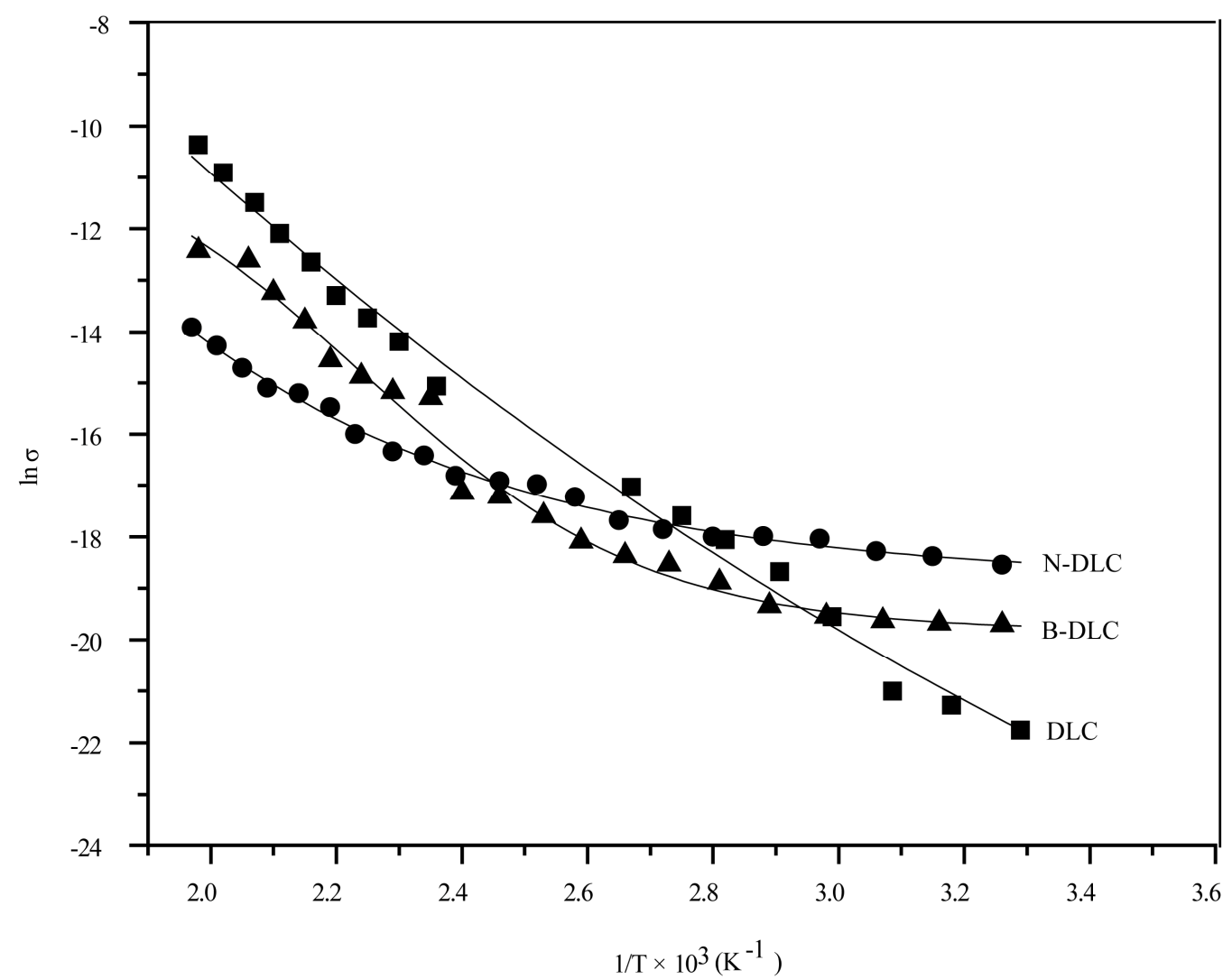

Figure 6. In $\sigma$ vs. 1/T plots of undoped a:DLC, a:N-DLC and a:B-DLC films. 
above the Fermi level $\left(\mathrm{E}_{\mathrm{F}}\right)$ and thus displaced the Fermi level towards extended state conduction band $\left(\mathrm{E}_{\mathrm{C}}\right)$. Activation energy $\left(\mathrm{E}_{\mathrm{a}}\right) \mathrm{n}$ can be identified with $\left(\mathrm{E}_{\mathrm{C}}-\mathrm{E}_{\mathrm{F}}\right)_{0}$ i.e. the energy difference between extended states and Fermi level extrapolated to $\mathrm{T}=0$. Similarly, boron doping increased p-type conductivity shifting the Fermi level towards the extended state valance band $\left(\mathrm{E}_{\mathrm{V}}\right)$. Activation energy $\left(E_{a}\right) p$ in this case can be expressed as $\left(E_{F}-E_{V}\right)_{0}$. The values of activation energies were found to be 0.75 $\mathrm{eV}$ for undoped a:DLC film, $0.32 \mathrm{eV}$ for a:N-DLC film and $0.58 \mathrm{eV}$ for a:B-DLC films. At higher temperatures conductivity in a:N-DLC and a:B-DLC films decreased in comparison with undoped films, which could be observed from Figure 6. At temperatures higher than $360 \mathrm{~K}$ for a:N-DLC and $340 \mathrm{~K}$ for a:B-DLC, conductivity became lower than that of undoped DLC. At these temperatures impurity levels became empty, and as the band gap increased due to doping, hence conductivity decreased with respect to undoped films.

\section{Conclusion}

Amorphous diamond like carbon films were deposited successfully on non-conductive glass as well as Si substrates by the electrolysis of methanol-camphor solution with the help of wire mesh electrode. Nitrogen and boron doping of the a:DLC films were achieved by using urea and boric acid with the precursor solution. FTIR spectrum of undoped a:DLC film showed the typical vibrations for tetrahedrally bonded carbon. The IR spectra of a:N-DLC and a:B-DLC films suggested incorporation of nitrogen and boron in DLC matrix. Optical measurements in UV-VIS-NIR region showed an increase in the optical energy band gap in a:N-DLC film, from $1.0 \mathrm{eV}$ in the undoped film to $2.12 \mathrm{eV}$ and in a:B-DLC film to 2.0 $\mathrm{eV}$. The films showed high transparency in visible region. Room temperature conductivity was increased by two orders of magnitude in a:N-DLC films and one order of magnitude in a:B-DLC films. Incorporation of nitrogen and boron reduced the electrical activation energy of the films from $0.75 \mathrm{eV}$ for a:DLC to $0.32 \mathrm{eV}$ and $0.58 \mathrm{eV}$ respectively for doped films.

\section{REFERENCES}

[1] J. C. Angus and C. C. Hayman, "Low-Pressure, Metastable Growth of Diamond and Diamondlike Phases," Science, Vol. 241, No. 4868, 1988, pp. 913-921. doi:10.1126/science.241.4868.913

[2] J. C. Angus, "Diamond and Diamond-Like Films," Thin Solid Films, Vol. 216, No. 1, 1992, pp. 126-133. doi:10.1016/0040-6090(92)90881-B

[3] D. Dutta, K. K. Chattopadhyay, J. Dutta, S. Chaudhuri and A. K. Pal, "Optical Properties of Diamond-Like Transitional Films Produced by DC Plasma Deposition of
Acetylene," Materials Letters, Vol. 18, No. 3, 1993, pp. 114-118. doi:10.1016/0167-577X(93)90108-A

[4] S. Kumar, C. M. S. Rauthan, P. N. Dixit, K. M. K. Srivatsa, M. Y. Khan and R. Bhattacharyya, "Versatile Microwave PECVD Technique for Deposition of DLC and Other Ordered Carbon Nanostructures," Vacuum, Vol. 63, No. 3, 2001, pp. 433-439. doi:10.1016/S0042-207X(01)00362-1

[5] S. Bhattacharyya, K. Walzer, M. Hietschold and F. Richter, "Nitrogen Doping of Tetrahedral Amorphous Carbon Films: Scanning Tunneling Spectroscopy," Journal of Applied Physics, Vol. 89, No. 3, 2001, pp. 1619-1625. doi:10.1063/1.1339854

[6] Y. Hayashi, G. Yu, M. M. Rahman, K. M. Krishna, T. Soga, T. Jimbo and M. Umeno, "Spectroscopic Properties of Nitrogen Doped Hydrogenated Amorphous Carbon Films Grown by Radio Frequency Plasma-Enhanced Chemical Vapor Deposition," Journal of Applied Physics, Vol. 89, No. 12, 2001, pp. 7924-7931. doi:10.1063/1.1371268

[7] M. Allon-Alaluf and N. Croitoru, "Nitrogen and Iodine Doping in Amorphous Diamond-Like Carbon Films," Diamond and Related Materials, Vol. 6, No. 5-7, 1997, pp. 555-558. doi:10.1016/S0925-9635(96)00736-4

[8] C. L. Tsai, C. F. Chen and C. L. Lin, "Characterization of Phosphorus-Doped and Boron-Doped Diamond-Like Carbon Emitter Arrays," Journal of Applied Physics, Vol. 90, No. 4847, 2001, pp. 4847-4851. doi:10.1063/1.1408587

[9] S. C. H. Kwok, J. Wang and P. K. Chu, "Surface Energy, Wettability, and Blood Compatibility Phosphorus Doped Diamond-Like Carbon Films," Diamond and Related Materials, Vol. 14, No. 1, 2005, pp. 78-85. doi:10.1016/j.diamond.2004.07.019

[10] Sk. F. Ahmed, D. Banerjee and K. K. Chattopadhyay, "The Influence of Fluorine Doping on the Optical Properties of Diamond-Like Carbon Thin Films," Vacuum, Vol. 84, No. 6, 2010, pp. 837-842. doi:10.1016/j.vacuum.2009.11.009

[11] S. Kundoo, P. Saha and K. K. Chattopadhyay, "Synthesis of Tin-Incorporated Nanocomposite Diamond Like Carbon Films by Plasma Enhanced Chemical Vapor Deposition and Their Characterization," Journal of Vacuum Science and Technology B, Vol. 22, No. 6, 2004, pp. 27092714.

[12] J. T. Jiu, L. P. Li, C. B. Cao and H. S. Zhu, "Deposition of Diamond-Like Carbon Films by Using Liquid Phase Electrodeposition Technique and Its Electron Emission Properties," Journal of Materials Science, Vol. 36, No. 24, 2001, pp. 5801-5804. doi:10.1023/A:1012951904662

[13] S. Kundoo, P. Saha and K. K. Chattopadhyay, "Electron Field Emission from Nitrogen and Sulfur-Doped Diamond-Like Carbon Films Deposited by Simple Electrochemical Route," Materials Letters, Vol. 58, No. 30, 2004, pp. 3920-3924. doi:10.1016/j.matlet.2004.08.018

[14] S. Kundoo, A. N. Banerjee, P. Saha and K. K. Chattopadhyay, "Synthesis of Crystalline Carbon Nitride Thin Films by Electrolysis of Methanol-Urea Solution," Materials Letters, Vol. 57, No. 15, 2003, pp. 2193-2197. doi:10.1016/S0167-577X(02)01172-2 
[15] K. Chakrabarti, R. Chakrabarti, K. K. Chattopadhyay, S. Chowdhuri and A. K. Pal, "Nano-Diamond Films Produced from CVD of Camphor," Diamond and Related Materials, Vol. 7, No. 6, 1998, pp. 845-852. doi:10.1016/S0925-9635(97)00312-9

[16] Q. Fu, J. T. Jiu, C. B. Cao, H. Wang and H. S. Zhu, "Electrodeposition of Carbon Films from Various Organic Liquids," Surface and Coating Technology, Vol. 124, No. 2-3, 2000, pp. 196-200.

doi:10.1016/S0257-8972(99)00658-1
[17] J. C. Manifacier, M. De Murcia, J. P. Fillard and E. Vicario, "Optical and Electrical Properties of $\mathrm{SnO}_{2}$ Thin Films in Relation to Their Stoichiometric Deviation and Their Crystalline Structure," Thin Solid Films, Vol. 41, No. 2, 1977, pp. 127-135. doi:10.1016/0040-6090(77)90395-9

[18] J. I. Pankove, "Optical Processes in Semiconductors," Prentice-Hall Inc., Upper Saddle River, 1971.

[19] N. F. Mott and E. A. Davis, "Electronic Processes in Non-Crystalline Materials," Clarendon Press, Oxford, 1979. 